\title{
Agriculture and GMOs: challenges past and present
}

\author{
KAZIMIERZ GRZEŚKOWIAK \\ DNA Matrix Systems, Los Angeles, USA \\ e-mail: kaziu@uclabruins.com
}

\begin{abstract}
The biotechnological application of genetically modified organisms (GMOs) in agriculture has increased to help improve the production of vegetable protein and to prevent a myriad of possible viruses resulting from genetic mutation. Among other products of GMO biotechnology are materials for medical treatment and pharmaceuticals. The movement has increased concern and discussion about the risk and profitability of reprogramming genetic pathways for the cultivation of plants and vegetables. This paper provides a brief overview of different perspectives on the topic relating it to aspects of pioneering agro-biotechnology and human function viewed from the standpoint of an outsider to the world of GMO agriculture.
\end{abstract}

Key words: GMO, agriculture, biotechnology

\section{Introduction}

Scientific advances, particularly in molecular biologyhave undeniably had a great impact on increasing the production of food, energy, and textiles and have generally changed human life styles.

Despite the obvious advantages, in situations where questions may arise of, for example, how far can beneficial advances be maintained and what can go wrong when unanticipated developments occur, scientists are often challenged, and frequently risk being severely criticised. Luckily, various uncertainties and doubts and their particular causes can usually be explained and dissipated with the help of expert knowledge from different fields of science.

Being able to predict certain research avenues that later on, directly or indirectly, prove to be right or useful, is always a rewarding and fascinating part of a researcher's work. One of many such examples worth mentioning is the important work conducted by a team led by Kazimierz Wierzchowski, Andrzej Legocki and others that prepared the ground for genetic engineering and GMO biotechnology. That early project is of much significance, especially in the light of recent important research in agriculture that provides opportunities for increasing crop yields (Wierzchowski et al., 1989).
The main issue is the question of how to stimulate the economy controlling, at the same time, its expansion so that it will satisfy human needs but without an excessive distortion of established natural patterns.

Koji Nakanishi in his autobiography (Nakanishi, 1991) recalls a conversation with a colleague concerning an interesting question: what do you think about science, does chemistry help the human race or harm it? His response was, "I am very optimistic about the future of organic chemistry. The criticism that chemistry is the cause of pollution and other evils is a short-sighted view". He further continued, that in an interdisciplinary era, if we want to solve the mode of action of bioactive compounds for the purpose of uncovering the mysteries of life, science needs to develop more sophisticated active compounds and better technologies.

Indeed, the practice of interdisciplinary study that began at the start of the $20^{\text {th }}$ century with the discovery of penicillin by Alexander Fleming has enabled researchers today to investigate the inner workings of cells. One of the greatest recent achievements has been stem cell experiments that may lead the way to new drug therapies for people in need.

However, genetic manipulation with plants is more complex because plants are the foundation of all human 
life on earth. In this field there will always be controversy about how agro-GMOs might jeopardize our health and environment.

It is not that science is inadequate for the task. It is because of the way the public see the problem.

A report by the EU-funded GMO research group (EU-funded GMO research 2001-2010) indicates how well the program is dedicated to meet challenges still common in certain countries, especially those linked to fighting poverty and disease. As a counterbalance, Michael Antoniou (Antoniou et al., 2012) argue that such programs are unreliable.

This article is about the current trend for GMO agriculture where researchers are highly motivated by the prospect of exciting new discoveries. On the other hand, successive failures may not only overshadow the initial successes but may also require years to fix. Nevertheless, such failures also offer advice as to how to avoid missteps in the future.

\section{Discussion}

Three decades ago scientists responded to ecological and energy problems encountered in agriculture due to the shortage of vegetable protein to meet human consumption needs.

As a result, new GMO techniques have been pursued in a number of areas: agriculture - to increase crop yields, in pharmacy - to discover new pharmaceuticals and elsewhere - to increase biofuel output (Weglenski and Twardowski, 2012). In the light of the numerous discoveries that quickly followed, and whose predominant objective was to improve both the quality of life, and the recently developed GMO agriculture, special attention must now be given to the preservation of the harmony of agro-biotechnology in ecological terms.

Fortunately, the scientific community is more cautious nowadays, and is aware of the need to protect the environment, which includes elimination of all undesirable side effects. Therefore, introducing reprogramed genetic biomechanistics using GMO techniques is performed with greater care to avoid negative impacts on the environment. It is important that in the race for new discoveries we must not ignore what nature is sometimes trying to tell us.

This presentation is a compilation of a collection of seven relevant research projects in one format issue to indicate the importance of agricultural research. It is, at the same time, a material for a discussion of the necessity of balancing the established patterns of mothernature with human desires for GMO agriculture.

The following bullet points are the main topics.

\section{GMO agriculture complexity}

With the innovation of all kinds of genetically engineered organisms, a concern is that, when we are consuming genetically fabricated agricultural products, what, if any, might the effects of this activity be on people and livestock.

On the positive side, GMO components have been found in a variety of applications, especially in the pharmaceutical industry for medical needs. Medicine treats people on an individual basis (hundreds of thousands), as opposed to the mass scale (hundreds of millions) who will be affected by the consumption of GMO agriculture products.

As with the advent of the cellular phone and its possible effects on the brain, more basic research on the application of GMOs in agriculture and the possible consequences would benefit us all. What is frightening, though, is that we do not yet know the future consequences of our present day actions, and yet we continue to produce and use some of the products in question.

GMO techniques in agriculture have been developed by a group of enthusiastic people who have been working zealously to boost agricultural crop yields and who were subsequently overwhelmed with some results, so the optimism has been high. However, being cautious is always a good thing and the GMO project should not be pushed but rather studied more carefully and viewed from various angles.

Science is at the nascent stages of understanding how plants and vegetables grow and develop, and how they detect and react to changes in an environment of molecular genetic modification. How they respond to sunlight and what wavelength is most important for specific metabolism. What components make seeds stronger and better for producing higher yields of crops?

Such projects and a number of related ones are currently being conducted in the laboratories of several research institutions around the world.

GMO agriculture is a huge task that certainly faces a number challenges, such as establishment of government regulations, allocation of a great amount of money 
required to build up an administration system, laboratories and controlling agencies. It is also essential that conditions surrounding the terms of legality and ethics of GMO systems need to be worked out (Twardowski, 2012; Twardowski and Małyska, 2012).

However, despite the best regulations, there is always the chance that such programs may turn out to be about commercial competitiveness and money. It could also be that one subsidy program would only lead to a new one to replace the first one. Wrongly managed or unnecessary spending may create organizational madness including a possible conflict of interest because of the unthought-of consequences of seemingly good ideas.

For such reasons perhaps, GMO agriculture programs in small-size countries should be executed tentatively and on a limited basis with the mutual understanding of the parties involved. Then, any long range possible negative effects on future generations will surely be avoidable and, in any case, going slowly would do it good.

The history of agricultural science and farming as well the trends of the last 60 years is an interesting story of changes. In the 1950s an increase in agricultural productivity was achieved mainly by using chemicals and later in combination with botany and engineering. Noteworthy is an agricultural research project on recognizing the phenomena of airborne nitrogen fixation of lupine plants.

Not directly linked to agriculture, there is the story of successful human insulin production, one of the highlights of biochemical sciences, and the story of the restoration of Ciconia Boyciana.

\section{Public opinion on GMO agriculture}

Cautioned by the impact of DDT and other agricultural chemicals used in the past, the public is more aware of the possible negative consequences from the consumption of GMO agricultural products.

In England and in the United States, people in increasing numbers are concerned about GMO products and even turn away from conventionally grown fruits and vegetables. Their motto is a return to organically grown produce because the use of pesticides and phosphate/ nitrogen fertilizers contaminate drinking water as well agricultural products. Production of organic and environmentally-friendly food is always vital even if there may still be some limits to production.

\section{Lupinus and sugarcane}

Attempts have aimed to develop sustainable agricultural production, which could be adapted from the biological mechanism of nitrogen fixation in lupines to such a symbiosis in edible plants and vegetables.

From the studies of lupine symbiosis we learned: (i) how difficult it is to mimic mother nature when we attempt to copy and transport genetic machinery from lupines to cultivate edible plants acquiring airborne nitrogen, (ii) that the complexity of this process may be underscored by the action of small micro-organisms and microelements, e.g. such as iron (Strożycki et al., 2007). This is a steadily progressing project about how to find the link between nitrogen fixation and formation of side products, e.g. bitter alkaloids. To know the distribution of alkaloids in stems and leaves and what chemical components are responsible for their formation seems to be an interesting avenue to pursue if it is not already on its way.

In Brazil, sugarcane is cultivated on a large scale although not as a food supplement, but rather for production as a fuel. Selection and inoculation with nitrogen fixing bacteria has yielded sugarcane that takes half the nitrogen needed for its growth from the air. This breakthrough, while good, regrettably has created the undesirable side effect of deforestation (one of mini-factors of climate change) as a result of profitable biofuel production.

\section{Great famine in Ireland}

An example of imperfect human agricultural activity but excusably unintentional comes from Ireland. At the peak of farming, most potatoes were aggressively grown from one end of the country to the other and became the staple food. As a result, the population of Ireland grew fantastically fast. But mass production of potatoes yielded unpredicted and unwanted results. The proximate cause of the famine was a potato disease commonly known as potato blight caused from oversized fields of this vegetable. During the famine, approximately one million people died and a million more emigrated from Ireland, causing catastrophic social, political, and economic upheaval.

\section{Huntington's disease: origins and research}

One of the mysterious phenomena of a genetic nature is a neurodegenerative genetic disorder, which disables motor coordination. Symptoms of this disease 
were first noticed over a century ago and reported by a number of scientists from the observation of several families living in villages in Venezuela and Norway.

George Huntington was the first to publish his observations (Huntington, 1872). The first page of his article, these days a curio not easy to find in libraries, can be retrieved from the internet thanks to the Nature Publishing Group.

It was not until 1993 when the key results were reported on a gene sequence with an expanded CAG repeat called huntingtin located on one of the chromosome called 4p16.3 in Huntington's disease patients (MacDonald et al., 1993).

CAG repeats exhibit dramatic instability when transmitted to a subsequent generation by increasing the number of CAG triplets in offspring. One CAG triplet is the genetic code for the amino acid L-glutamine. Exceeding a normal range of about 25 to 40 and more repeats causes neurodegenerative disorder, which accumulates aggregated huntingtin.

We studied the structural function of the $\mathrm{CAG}$ repeat using $\mathrm{CG}(\mathrm{CAG})_{4} \mathrm{CG} / \mathrm{CG}(\mathrm{CTG})_{4} \mathrm{CG} 16$-mer as a model to find a proper DNA binding drug. The gel electrophoresis measurements, $\mathrm{CD}$ spectra measurements and the x-ray crystal structure results, although still preliminary (Grześkowiak et al., 2004), provide us with some information on the stretching properties of CAG triplets leading to structural rearrangements into a possible four chains tetrad formation, which we thought may also occur on an expended L-poly glutamine chain.

Experiments conducted by Perutz's group (Perutz et al., 1994) using computer modeling and CD spectroscopy measurements of synthetic poly(L-glutamine) showed that instead of quadruplex structures (as we suggested at the Workshop of Hereditary Disease Foundation, Islamorada Key West 1994) the peptide forms beta-sheets held together by hydrogen bonds between main chains and side chains of amides. The protein usually exists in its normal conformation to work the genetic machinery. However, in proteins with an extended polyglutamine chain over 40 glutamine residues deformation of the polyglutamine track occurs that flips its normal conformation into an abnormal one. This is caused by association of the extended L-polyglutamine chain into the dimer beta-sheet postulated by Perutz.

In addition, there are numerous data that indicate tautomerization of polyL-glutamine side chains and for- mation of multimember rings varying in chain length. Such conformational rearrangements form later harder to be solubilized huntingtin protein.

Recently, progress has been made and preliminary results offer new hope for curing Huntington's disease using stem cell procedures.

Nevertheless, the cause of such isolated phenomena as abnormalities in the genetic pathway of CAG triplet extensions is still not known. It could be a virus or genetic material such as foreign proteins, which happen to be the motor for the expansion of CAG over regular length. The origins of the disease may also come from sources such as agricultural products or external forces that have entered the human body, misleading the genetic scheme established by nature.

Nancy Wexler at Columbia University is credited for the discovery of the location of the gene that causes Huntington's disease. She advocates a research project on how to cure Huntington's disease through the Hereditary Disease Foundation, which has made tremendous efforts to help those who suffer from this neurological disorder. Her studies and the work of others are examples of how difficult it is to repair something that has been going wrong for generations.

The huntingtin story is addressed here in an effort to search for ideas and tools that could be used to bring expansion of CAG repeats under control and stop instability of the CAG repeat in offspring. Also, it gives us a moment to think about the mysteriously initiated and wrongly processed CAG expansion in the human genetic machinery of inhabitants of just two villages of Venezuela and Norway over a century ago.

So we should be aware that despite numerous positive results indicating the harmless nature of GMO agricultural products for humans, biological manipulation in food production may still carry risk, complications and unknown consequences for generations to come.

\section{Insulin project}

We can consider aspects of GMO matters with a rhetorical phrase "what scientists in a big country do for good, may not necessary work well in the hands of a small group of scientists in medium-sized countries." An example is the insulin project for in vitro production of this hormone. The project was successful in the United States where circumstances and the timing were crucial to implement the insulin system to work effi- 
ciently. For instance, the chemical synthesis of the DNA key components was just well enough established to make DNA oligomers of good purity and desired sequences.

The insulin project is worth mentioning as it was an international effort starting with the work of the PolishGerman physician Oscar Minkowski who, in collaboration with Joseph von Mering back in 1889, established for the first time a relationship between the pancreas and diabetes. It took many years to isolate insulin from pig pancreas and decades to successfully produce the first genetically-engineered, synthetic "human" insulin in a laboratory. This was achieved by Herbert Boyer using E. coli. (Boyer, 1978). This great project was also possible thanks to Keichi Itakura's laboratory at the City of Hope, where Polish scientists - then postdoctoral fellows - Adam Kraszewski (Kraszewski, 2009), Piotr Dembek and Ryszard Kierzek were members of a team that synthesized DNA oligomers for recombination techniques in somastatin, insulin and interferon projects.

For nearly a decade Bioton. S.A. have produced the insulin in Poland.

\section{Remarks and Ciconia boyciana}

In the case of fast growing new farming systems the big question remains: "to copy or not to copy" the industrialization of agriculture from the pioneering countries. Perhaps for medium-sized countries it would be reasonable rather to do more basic research into these matters and save success for later. Also, considering other alternatives from our own agricultural capacity as well as from other countries is always a good approach. For instance, it would be worthwhile taking a closer look at the farming methods and food processing practiced in England and Japan.

Examples of today's Japanese agricultural system can be related to the restoration of the Oriental White Stork (Ciconia boyciana). These birds began to decrease in number to nearly extinction mainly due to agricultural chemicals, habitat-loss and deterioration. The last living storks were captured and kept in captivity to prevent total extinction until the reintroduction project took place at non-pesticide farming sites, focused on the restoration of the rural environment. The storks were released from captivity into the wild in 2005 and the population since then has been growing.
Interestingly, the stork extinction prevention program in Poland is well executed and it is a fine subject of environmental education on ecological harmony.

\section{Conclusions}

In the past decades we have witnessed how science has revolutionized agriculture by doubling or even tripling crop yields. However, the question still remains, can it feed the world's growing population without causing serious damage, and if no, what would be the extent of such damage?

It sounds like an unending adventure at the edge of uncertainty because it carries a risk that research for new disease-resistant and high-yielding varieties can never rest since genetic mutations forever produce new pests and diseases.

\section{Acknowledgments}

Part of this work (experiments on CAG) has been carried at the Molecular Biology Institute, UCLA Los Angeles and at Osaka University of Pharmaceutical Sciences, thanks to funds from the Japanese Society for the Promotion of Sciences.

\section{References}

A decade of EU-funded GMO research (2010). (2001-2010), Directorate-General for Research and Innovation. Biotechnologies, Agriculture, Food EUR 24473 EN.

Antoniou M., Robinson C., Fagan J. (2012) GMO Myths and True. An evidence-based examination of the claims made for the safety and efficacy of genetically modified crops, Earth Open Source, London.

Boyer H. et al. (1978) First Successful Laboratory Production of Human Insulin Announced. News Release. Genentech 1978-09-06.

Grześkowiak K. et al. (2004) Function of AGCA tetrads in $(C A G)_{n}$ repeats. Nucl. Acids Res. Supplement 48: 291292.

Huntington G. (1872) On Chorea. Med. Surg. Rep. Philadelphia 26(15): 317-321.

MacDonald M.E. et al. (1993) The Huntington's Disease Collaborative Research Group: Novel Gene Containing a Trinucleotide Repeat That is Expanded and Unstable on Huntington's Diseases Chromosomes. Cell 72: 971-983.

Kraszewski A. (2009) Początki inżynierii genetycznej. Insulina człowieka $w$ bakteriach. In: Od syntezy chemicznej do biologii syntetycznej, OWN, Poznań, pp. 95-103.

Nakanishi K. (1991) A Wondering Natural Products Chemist. In: Profiles, Pathways and Dreams, ed. Seeman J.I., Amer. Chem. Soc., Washington.

Perutz M.F., Johnson T., Suzuki M., Finch J.T. (1994) Glutamine repeats as a zipper polars: Their possible role in in- 
herited neurode-generative diseases. Proc. Natl. Acad. Sci., USA 91: 5335-5358.

Stróżycki P.M., Szczurek A., Lotocka B., Figlerowicz M., Legocki A.B. (2007). Ferritins and nodulation in Lupinus luteus: iron management in indeterminate type nodules. J. Exp. Bot. 58(12): 3145-3153.

Twardowski T. (2012) Aspekty spoleczne i prawne biotechnologii, Polska Akademia Nauk.

Twardowski T., Małyska A. (2012) Social and legal determinants for the marketing of GM products in Poland. New Biotechnology 29(3): 249-254.
Węgleński P., Twardowski T. (2012). Nowe technologie szansa polskiej gospodarki. Nauka (1): 7-9.

Węgleński P., Twardowski T. (2012). New technologies as opportunities for the Polish economy: GMOs for industry and agriculture. Biotechnology 93(1): 7-8.

Wierzchowski K. et al. (1989) Propozycje dotyczace strategii i metod sterowania rozwojem biotechnologii po $1990 \mathrm{r}$. Biotechnologia 1(3): 3. 